\title{
O Programa Nacional de Alimentação Escolar em Santana do Livramento (RS): Desafios para a Adequação à Lei dos $30 \%$
}

\author{
Alessandra Troian \\ Universidade Federal do Pampa/Campus de Santana do Livramento - \\ Santana do Livramento - RS - Brasil \\ ORCID: http://orcid.org/0000-0001-8207-6436 \\ Raquel Breintenbach \\ Instituto Federal de Educação, Ciência e Tecnologia do Rio Grande do \\ Sul/campus Sertão - Sertão - RS - Brasil \\ ORCID: http://orcid.org/0000-0002-9431-3766
}

\section{Resumo}

O Programa Nacional de Alimentação Escolar (PNAE) é uma importante política pública de alimentação e nutrição no Brasil. Ao estabelecer legalmente que 30\% dos recursos federais repassados para a merenda escolar devem ser empregados na compra de produtos da agricultura familiar, a lei contribui para o fortalecimento da categoria social e para o desenvolvimento local. Neste sentido, a pesquisa visa analisar como Santana do Livramento tem usado os recursos do PNAE e elencar os entraves e desafios na aquisição dos alimentos diretamente da agricultura familiar. Metodologicamente a pesquisa caracteriza-se como mista, com a coleta e análise de dados secundários obtidos no sítio oficial do Fundo Nacional de Desenvolvimento da Educação e dados primários, a partir de entrevistas. No período de 2010 a 2017 o município não cumpriu a Lei nº 11.947/2009, chegando ao máximo de utilização de $19,49 \%$ do recurso do PNAE para a compra direta da agricultura familiar. Os principais entraves para o cumprimento da lei são: a documentação necessária, a demora na elaboração e divulgação dos editais, a percepção de que o preço dos produtos é elevado, falta de documentação da agricultura familiar e desconhecimento dos gestores acerca dos alimentos produzidos localmente.

Palavras-Chaves: Mercados Institucionais. Agricultura Familiar. Segurança Alimentar.

\section{The National School Food Program in Santana do Livramento (RS): Challenges for the} Following of the $30 \%$

\section{Abstract}

The National School Feeding Program (PNAE) is an important public food and nutrition policy in Brazil. By legally establishing that 30\% of federal funds transferred to school lunches must be used to purchase products from family farming, the law contributes to the strengthening of the social category and to local development. In this sense, the research aims to analyze how Santana do Livramento has used the resources of the PNAE and list the 
obstacles and challenges in the acquisition of food directly from family farming. Methodologically the research is characterized as mixed, with the collection and analysis of secondary data obtained on the official website of the National Fund for the Development of Education and primary data, from interviews. In the period from 2010 to 2017 the municipality did not comply with Law No. 11,947 / 2009, reaching a maximum utilization of $19.49 \%$ of the PNAE resource for the direct purchase of family farming. The main obstacles to compliance with the law are: the necessary documentation, the delay in preparing and publishing the notices, the perception that the price of the products is high, the lack of documentation on family farming and the managers' lack of knowledge about the food produced locally.

Keywords: Institutional Markets. Family Agriculture. Food Security.

\section{El Programa Nacional de Alimentos Escolares en Santana do Livramento (RS): Desafíos para la Aptitud con la Ley del $30 \%$}

\section{Resumen}

El Programa Nacional de Alimentación Escolar (PNAE) es una importante política pública de alimentación y nutrición en Brasil. Al establecer legalmente que el 30\% de los fondos federales transferidos a los almuerzos escolares deben usarse para comprar productos de la agricultura familiar, contribuye al fortalecimiento de la categoría social y al desarrollo local. En este sentido, la investigación tiene como objetivo analizar cómo Santana do Livramento ha utilizado los recursos de PNAE y enumerar los obstáculos y desafíos en la adquisición de alimentos directamente de la agricultura familiar. Metodológicamente, la investigación se caracteriza por ser mixta, con la recopilación y análisis de datos secundarios obtenidos en el sitio web oficial del Fondo Nacional para el Desarrollo de la Educación y datos primarios, a partir de entrevistas. En el período 2010-2017, el municipio no cumplió con la Ley $N^{\circ} 11.947$ / 2009, alcanzando una utilización máxima del 19,49\% del recurso PNAE para la compra directa de la agricultura familiar. Los principales obstáculos para el cumplimiento de la ley son: la documentación necesaria, la demora en la preparación y publicación de los avisos, la percepción de que el precio de los productos es alto, la falta de documentación sobre la agricultura familiar y la falta de conocimiento de los gerentes sobre los alimentos producidos localmente.

Palabras clave: Mercados institucionales. Agricultura familiar. Seguridad Alimentaria.

\section{Introdução}

O PNAE é um programa universal e gratuito que atende, sem distinção, todos os alunos da educação básica matriculados em escolas públicas, filantrópicas e em entidades comunitárias conveniadas com o poder público, por meio da transferência de recursos financeiros (FNDE, 2014). O programa passou por reformulações importantes ao logo da sua história.

A principal alteração do programa se deu em 2009, a partir da criação da Lei $\mathrm{n}^{\circ} 11$ 11.947/2009 que regulamenta que 30\% dos recursos federais repassados para a merenda escolar devem ser empregados na compra de produtos da agricultura familiar. Assim, o programa atua na segurança alimentar e nutricional dos estudantes e fomenta o desenvolvimento sustentável, valorizando a cultura alimentar, alimentação saudável e alocação dos sistemas agroalimentares (PEDRAZA, et al., 2018; BASSO et al., 2019).

Através da compra da alimentação escolar diretamente da agricultura familiar local, o PNAE cria um canal para a comercialização de produtos inseridos ou 
não no mercado convencional, possibilitando desenvolver canais de comercialização alternativos para a agricultura familiar com o mercado institucional (MALINA, 2012; FNDE, 2017).

$\mathrm{O}$ acesso aos mercados institucionais pela agricultura familiar representa benefícios tanto para os agricultores, com o escoamento de sua produção, como para os estudantes, que passam a usufruir de alimentos de qualidade. Mesmo enfrentando entraves para escoar a sua produção, os agricultores familiares encontram no acesso aos mercados institucionais uma estratégia fundamental de comercialização (ROZENDO et al., 2014; SOARES et al., 2015).

Em Santana do Livramento, município localizado na metade sul do Rio Grande do Sul, a agricultura familiar sempre se fez presente, apesar do município ser conhecido pelas grandes propriedades rurais e pela produção pecuária. A agricultura familiar se desenvolveu as margens do agronegócio e não teve, ao longo da história, a atenção merecida do poder público (TROIAN; BREITENBACH, 2018).

Neste sentido, a presente pesquisa visa analisar como a gestão pública municipal de Santana do Livramento tem usado os recursos do Programa Nacional de Alimentação Escolar. Especificamente, buscou-se: a) identificar o montante, dentre os valores recebidos para a merenda escolar, usados para a compra dos alimentos diretamente da agricultura familiar; b) estabelecer um comparativo entre o percentual de recursos usados para a aquisição da merenda escolar da agricultura familiar em Santana do Livramento com as médias estaduais e nacionais; c) averiguar os entraves e desafios para o cumprimento da Lei $n^{\circ}$ Lei $n^{\circ} 11.947 / 2009$.

A pesquisa justifica-se pela carência de estudos que envolvem a agricultura familiar local. Tal carência é ainda maior quando se trata de pesquisas que abordem a gestão municipal e a legislação do Programa Nacional de Alimentação Escolar no que concerne a compra direta de alimentos produzidos pelos agricultores familiares locais.

\section{O PROGRAMA NACIONAL DE ALIMENTAÇÃO ESCOLAR E A AGRICULTURA FAMILIAR}

A seção discute acerca do papel dos mercados institucionais na oferta de alimentos para os programas de merenda escolar e a importância de tais mercados para o fortalecimento da agricultura familiar.

\subsection{O Programa Nacional de Alimentação Escolar}

A educação alimentar nas escolas brasileiras surgiu entre os anos de 1930 e 1940, através das reivindicações dos movimentos sociais. O Governo Federal reconhecia a importância da alimentação nas escolas como maneira de promover a permanência dos alunos e a diminuição da desnutrição infantil no país. Contudo, o governo não possuía recursos financeiros para a iniciativa (CHAVES; BRITO 2006).

Na década de 1950 a alimentação escolar começou a ser pensada como um programa público. Um dos marcos do processo foi o surgimento do Plano Nacional de Alimentação e Nutrição (PNAE), denominado Conjuntura Alimentar e o Problema da Nutrição no Brasil, o qual representava o primeiro programa de merenda escolar sob responsabilidade pública (FNDE, 2017). No início do programa, os alimentos 
eram oferecidos por organismos internacionais através de doações de alimentos industrializados como: leite em pó desnatado, farinha de trigo e soja. Com o passar do tempo as doações foram diminuindo e houve a necessidade do PNAE ser mantido com recursos brasileiros. Assim, a partir de 1960, o Governo Federal iniciou a compra de produtos para a alimentação escolar (CHAVES; BRITO, 2006).

No período de 1955 a 1993, o PNAE se caracterizou como um programa centralizado. A compra de gêneros alimentícios ocorria por meio de processo licitatório e o cardápio era definido pelo Ministério da Educação. Na década de 1990 o programa passou por sua primeira mudança, com a Lei $n^{\circ} 8.913$ de 12 de junho de 1994, descentralizando os recursos. Estados e municípios tornaram-se responsáveis pela execução dos recursos repassados ao programa (STEFANINI, 1997).

Com isso, ocorreram adaptações no programa de acordo com a realidade e as necessidades locais, promovendo a qualificação dos executores e a inserção de alimentos de qualidade e in natura (CHAVES; BRITO, 2006). A descentralização também permitiu a adaptação dos cardápios escolares às diferentes realidades regionais e incluiu profissional de nutrição na elaboração dos cardápios escolares (BELIK; SOUZA, 2009).

Desde 1998 o PNAE é gerido pelo Fundo Nacional de Desenvolvimento da Educação, uma autarquia do Ministério da Educação (MEC), atendendo às necessidades nutricionais dos estudantes em sala de aula, contribuindo para o crescimento, desenvolvimento, aprendizagem e rendimento escolar (CHAVES; BRITO, 2006).

O PNAE é o programa de maior longevidade do país na área de segurança alimentar e nutricional e é um dos maiores programas de alimentação e nutrição do mundo (PEIXINHO, 2013). A política da alimentação escolar foi implementada no Brasil em 1955 e, com as diversas reestruturações, passou de uma política de suplementação alimentar para uma política pública de desenvolvimento (FNDE, 2017; PEREIRA et al., 2018).

A mudança do PNAE, a partir da Lei $n^{\circ} 11.947$ de 16 de junho de 2009, constitui-se como um passo em prol da agricultura familiar, ao determinar que pelo menos $30 \%$ do valor destinado à alimentação escolar brasileira deve ser investido na compra direta de produtos oriundos da agricultura familiar (TRICHES, 2010; FNDE, 2018):

\footnotetext{
Art. 14. Do total dos recursos financeiros repassados pelo FNDE, no âmbito do PNAE, no mínimo 30\% (trinta por cento) deverão ser utilizados na aquisição de gêneros alimentícios diretamente da agricultura familiar e do empreendedor familiar rural ou de suas organizações, priorizando-se os assentamentos da reforma agrária, as comunidades tradicionais indígenas e comunidades quilombolas (BRASIL/FNDE, 2009, p.02).
}

A atual configuração do PNAE apoia um modelo de desenvolvimento que promove crescimento econômico, justiça social, conservação ambiental e saúde pública (TRICHES; SCHNEIDER, 2010). O mercado institucional é uma importante política de desenvolvimento local, fortalece a agricultura familiar pelo escoamento de sua produção e proporciona alimentação segura e saudável para os estudantes (BRASIL, 2009; BRASIL, 2016; MALINA, 2012; BECKER; SACCO DOS ANJOS, 2015).

No Brasil, o marco dos mercados institucionais foi o ano de 2003, com implantação do Programa de Aquisição de Alimentos da Agricultura Familiar (PAA), 
Lei 10.696/03, que fomentou a revisão dos Programas Alimentares, como o da Alimentação Escolar (FNDE, 2014). O PAA se insere no marco do programa "Fome Zero", em que o governo federal assegura a compra dos produtos da agricultura familiar ("beneficiários produtores") que são destinados aos "beneficiários consumidores" (asilos, creches, albergues, hospitais, etc) (BRASIL, 2009). Com isso, incentiva a agricultura familiar, promove a inclusão social no campo e garante alimento às populações em situação de insegurança alimentar (MDA, 2017). Os resultados positivos do programa influenciaram as alterações no PNAE, com a Lei de 2009.

A história do programa de alimentação escolar brasileiro incentiva a substituição de um modelo de consumo e produção de alimentos industriais processados, por outro de alimentos da agricultura familiar (TRICHES, 2010). No entanto, para que a política tenha efeito é preciso que a lei seja cumprida e os recursos do PNAE sejam utilizados para a aquisição de alimentos frescos, locais, sazonais e de acordo com os hábitos alimentares de cada região (TRICHES, 2010; PEREIRA et al., 2018). Com o objetivo de sintetizar os principais marcos da política de alimentação escolar, apresenta-se o Quadro 1.

Quadro 1- Principais marcos da política de alimentação escolar brasileira

\begin{tabular}{|c|c|}
\hline Período & Marco histórico/ Acontecimento \\
\hline $\begin{array}{c}1930 \mathrm{a} \\
1940\end{array}$ & $\begin{array}{l}\text { A partir das reinvindicações dos movimentos sociais passa-se a pensar na educação } \\
\text { alimentar nas escolas brasileiras. }\end{array}$ \\
\hline $\begin{array}{l}\text { Década } \\
1950\end{array}$ & $\begin{array}{l}\text { A alimentação escolar pensada como programa público. } \\
\text { Criação do Plano Nacional de Alimentação e Nutrição } \\
\text { Decreto } n^{\circ} .37 .106 \text { - Campanha da Merenda Escolar (CME). }\end{array}$ \\
\hline $\begin{array}{c}1955 a \\
1993\end{array}$ & $\begin{array}{c}\text { Programa de alimentação escolar centralizado: compra de gêneros alimentícios por } \\
\text { processo licitatório e cardápio definido pelo Ministério da Educação. }\end{array}$ \\
\hline $\begin{array}{l}1976 \text { a } \\
1979\end{array}$ & $\begin{array}{l}\text { A partir de 1976, embora financiado pelo Ministério da Educação e gerenciado pela } \\
\text { Campanha Nacional de Alimentação Escolar, o programa era parte do II Programa } \\
\text { Nacional de Alimentação e Nutrição (Pronan). } \\
\text { Em } 1979 \text { passou a ser chamado de Programa Nacional de Alimentação Escolar. }\end{array}$ \\
\hline $\begin{array}{l}\text { Década } \\
1990\end{array}$ & $\begin{array}{l}\text { Lei } \mathrm{n}^{\circ} 8.913 / 1994 \text { - descentralização dos recursos do PNAE: secretarias municipais e } \\
\text { estaduais de educação assumem o processo de compra da alimentação escolar. } \\
\text { Em } 1998 \text { o PNAE passo a ser gerido pelo FNDE/MEC. }\end{array}$ \\
\hline $\begin{array}{l}\text { Anos } \\
2000\end{array}$ & $\begin{array}{l}\text { Criação do Programa de Aquisição de Alimentos em 2003; Reformulação do } \\
\text { Programa Nacional de Alimentação Escolar, em } 2006 \text { - instrumento de segurança } \\
\text { alimentar e desenvolvimento sustentável, viabilizando compras públicas dos } \\
\text { agricultores familiares locais; Renovação do PNAE, a partir da Lei n } 11.947 \text { de } 16 \text { de } \\
\text { junho de } 2009 \text { - determina que pelo menos } 30 \% \text { do valor destinado à alimentação } \\
\text { escolar brasileira deve ser compra direta de produtos oriundos da agricultura familiar. }\end{array}$ \\
\hline
\end{tabular}

Fonte: Elaborado pelos autores com base no referencial teórico.

É possível observar os avanços que a alimentação escolar conquistou ao longo dos anos, que possibilitou que a política de suplementação alimentar se transformasse em política pública de desenvolvimento. A seção a seguir contextualiza a importância do PNAE para os agricultores familiares.

\subsection{A agricultura familiar e o Programa Nacional de Alimentação Escolar}

A agricultura familiar obteve espaço e importância nas últimas três décadas por meio do reconhecimento estatal e acadêmico, através de estudos, políticas de 
governo e a partir da pressão dos movimentos sociais (SCHNEIDER, 2004; SABOURIN et al., 2009). A categoria social agricultura familiar compreende todas as atividades agrícolas de base familiar, é a forma dominante de agricultura no setor de produção de alimentos, seja em países desenvolvidos ou em países em desenvolvimento (FAO, 2014).

Apesar da relevância da agricultura familiar na organização e na estruturação do espaço agrário no Brasil, as políticas públicas específicas de estímulos aos agricultores familiares foram criadas somente a partir do Programa Nacional de Fortalecimento da Agricultura Familiar (PRONAF), em 1995 (AZEVEDO; PESSÔA, 2011).

A agricultura familiar enfrenta dificuldades para escoar a sua produção, sendo a comercialização a principal. Políticas públicas como o PNAE contribuem na aquisição dos gêneros alimentícios direto dos agricultores familiares locais e é uma forma de impulsionar o desenvolvimento rural e a segurança alimentar (ROZENDO et al., 2014). Assim, o PNAE se tornou um instrumento de fortalecimento da agricultura familiar, o encontro entre alimentação escolar e agricultura familiar (SCHNEIDER, ESCHER, 2011; FNDE, 2017).

No entanto, apesar de apresentar inúmeras conquistas, a implementação e operacionalização do PNAE apresentam obstáculos. De acordo com Müller (2010), o PNAE possui complexidade própria, com uma série de especificidades como a multiplicidade de atores e arranjos institucionais em que é executado. Os gargalos a serem enfrentados pelos agricultores familiares também dificultam sua permanência nas atividades vinculadas ao programa.

Assim, ao se implementar programas como os mercados institucionais, torna-se imprescindível o compromisso dos atores sociais envolvidos (SCHNEIDER, 2003; SABOURIN, 2009). Ou seja, o comprometimento deve ocorrer por parte dos diversos atores sociais que se fazem presentes, a saber: os estudantes que passam a consumir alimentos de qualidade, de acordo com a época do ano e com os valores culturais locais; os agricultores familiares que têm mais tranquilidade em produzir alimentos, já que terão onde comercializar sua produção; e, os gestores públicos locais atuando na mediação entre escola e produtor, desenvolvendo e fortalecendo as políticas de incentivo ao desenvolvimento rural (CONTERATO et al., 2013).

\section{METODOLOGIA}

O estudo caracteriza-se como exploratório a partir do método misto, com etapa quanti e qualitativa (CRESWELL, 2007). Como técnicas de pesquisa foram usadas a revisão bibliográfica e a coleta e análise de dados primários e secundários.

Os dados secundários, referentes aos recursos repassados pela União via PNAE para Santana do Livramento/RS e os valores usados pelo município na aquisição de produtos diretamente da agricultura familiar, foram obtidos no sítio oficial do Fundo Nacional de Desenvolvimento da Educação. O período de análise foi de 2011 a 2017.

Já os dados primários foram coletados na segunda fase da pesquisa, após a análise dos dados secundários e da constatação da necessidade de verificar os entraves na aquisição dos alimentos da agricultura familiar. Para tanto, foram realizadas entrevistas semiestruturadas, a partir do critério da intencionalidade, 
com seis agentes, identificados como fundamentais na execução do PNAE, a saber: Secretária Municipal de Educação, técnica em nutrição, representando a Secretária Estadual de Educação, uma agricultora familiar, um professor de escola rural, um professor, ex-diretor de escola estadual e uma diretora de escola estadual. Para a realização das entrevistas utilizou-se de um roteiro elaborado previamente. As entrevistas ocorreram entre os meses de janeiro e março de 2019, elas foram gravadas, transcritas e analisadas.

Os dados secundários foram analisados por meio do método analítico, ou seja, os dados coletados foram representados de forma gráfica e proporcional. Já os dados primários foram analisados mediante o conteúdo das falas dos entrevistados, através da categorização (agrupamento), a partir de uma aproximação da metodologia proposta por Bardin (2004). Os discursos apresentados no decorrer do texto estão apresentados de acordo com a ordem que as entrevistas ocorreram.

\section{O DESEMPRENHO DO PNAE EM SANTANA DO LIVRAMENTO}

Nesta seção serão discutidos os resultados da pesquisa, tomando como base a coleta, sistematização e análise dos dados oficiais do PNAE. Primeiramente discutem-se os valores repassados pela União para o município de Santana do Livramento no período de 2011 a 2017 e os valores que efetivamente foram utilizados na aquisição de alimentos da agricultura familiar para alimentação escolar. Com exceção de 2014 e 2017, em que ocorreram reduções nos valores repassados para o município, os demais anos mostram acréscimo ascendente nos valores. De 2013 para 2014 ocorreu redução de $\mathrm{R} \$$ 60.892,00 repassados da União para Santana do Livramento. Já de 2016 para 2017 a redução foi de $R \$ 109.353,35$. A presente pesquisa empírica e pesquisas bibliográficas não foram conclusivas acerca das causas da redução nos repasses, não permitindo aos autores fazer associações ou terem conclusões.

No período analisado a utilização dos valores para aquisição da agricultura familiar foi inferior ao valor disponibilizado. Em 2011 nenhum recurso foi utilizado para compra dos agricultores familiares, passando a utilizar $\mathrm{R} \$ 26.924,00$ em 2012, reduzindo para $\mathrm{R} \$ 17.790,00$ em 2013 e para $\mathrm{R} \$ 360,30$ em 2014. A partir de 20140 município vem aumentando a escala de utilização do recurso e encerrou 2017 com a utilização de $\mathrm{R} \$ 126.523,00$. Conforme apresentado na Figura 01, a seguir. 
Figura 01 - Valores transferidos e valores usados pelo PNAE para a aquisição de alimentos da agricultura familiar Santana do Livramento/RS no período de 2011 a 2017

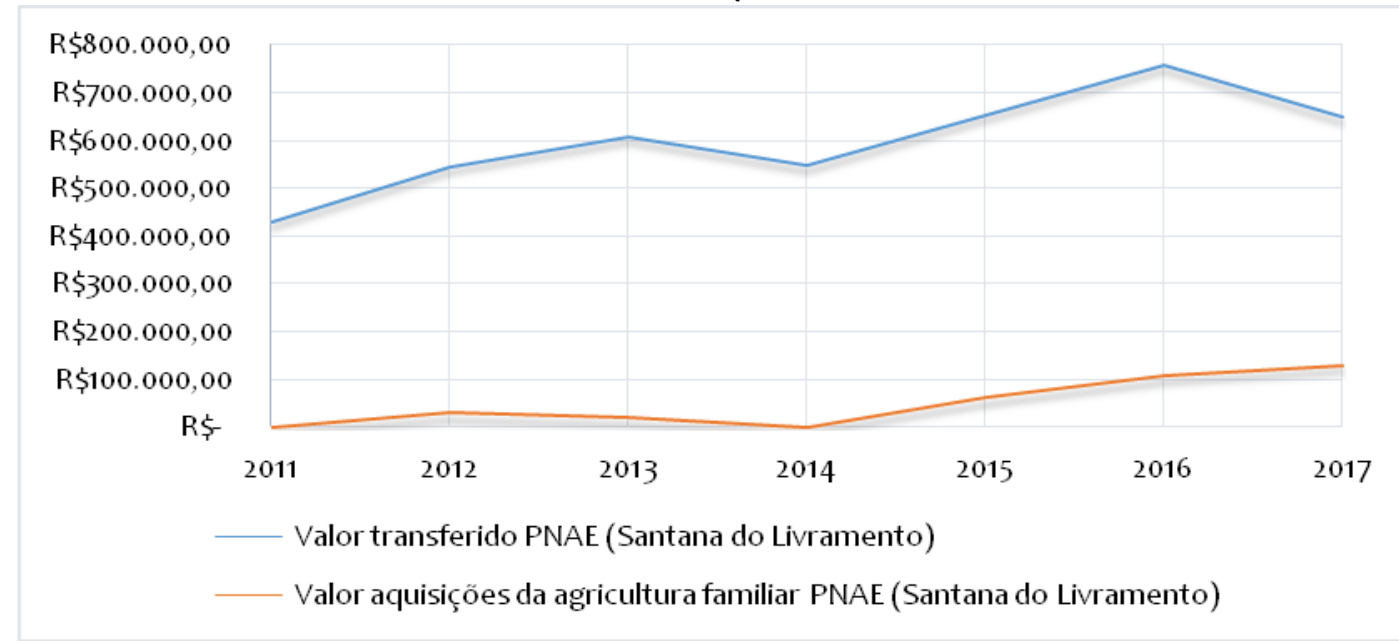

Fonte: Elaboração própria com os dados do FNDE (2017).

Mesmo no ano de 2017, que foi o ano em que o município de Santana do Livramento mais utilizou os recursos repassados pela união, ainda assim só correspondeu a 19,49\% (Figura 02). Nos anos de 2011 e 2014, por outro lado, 0 município utilizou $0 \%$ e $0,7 \%$ respectivamente.

É possível observa na Figura 02 que as médias anuais estadual e nacional de utilização do recurso do PNAE para aquisição da agricultura familiar são superiores às médias de Santana do Livramento. O RS supera a média nacional com média de utilização crescente até 2015 quando utilizou 46,59\% dos recursos, cumprindo as exigências legais. No ano de 2016 reduziu para 42\% e fechou o ano de $2017 \mathrm{com}$ cerca de $44 \%$. A média brasileira também foi crescente até 2015 , chegando a $28,26 \%$, mas reduzindo para 27,71\% em 2016 e com novo acréscimo em 2017, quando os municípios atenderam a legislação e utilizaram 34,36\%.

Figura 02 - Percentual dos recursos do PNAE usados para a aquisição da agricultura familiar em Santana do Livramento/RS

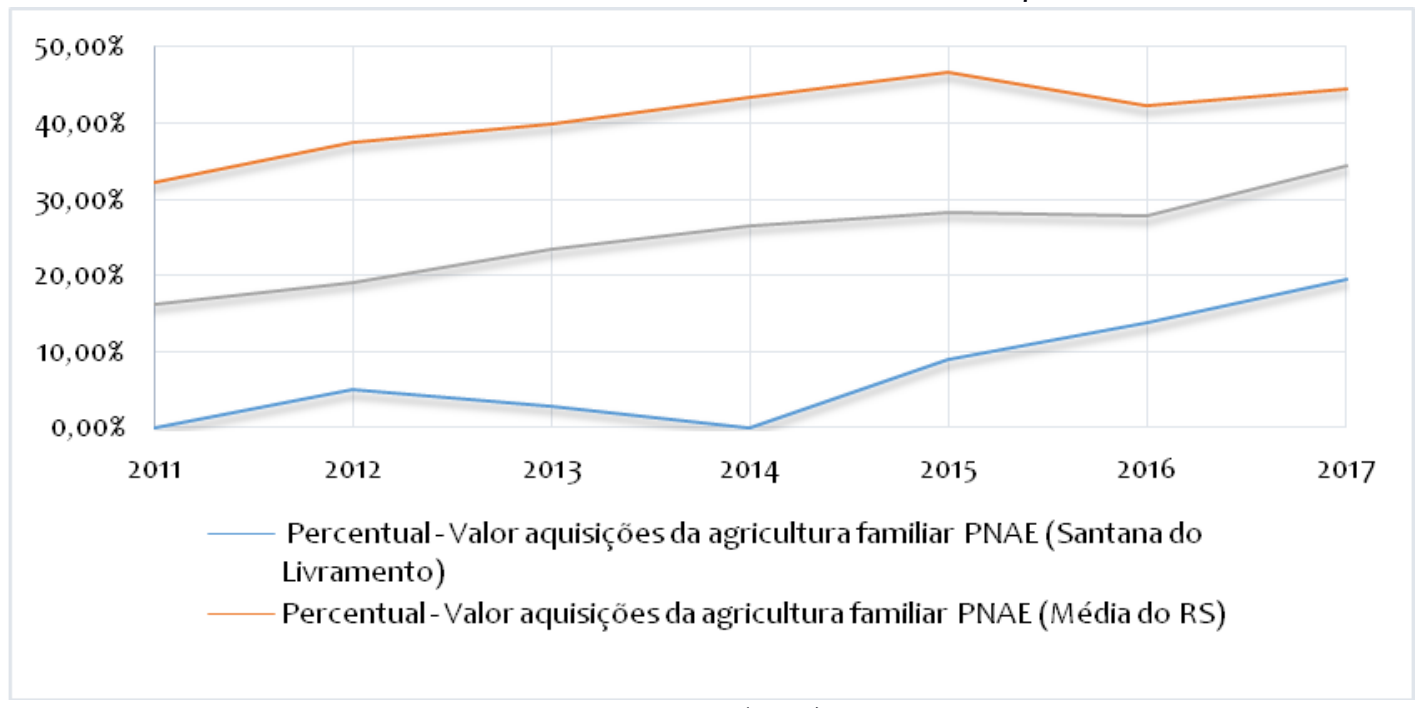

Fonte: Elaboração própria com os dados do FNDE (2017). 
$\mathrm{Na}$ Figura 03 é possível estabelecer um comparativo entre os valores repassados pelo FNDE para Santana do Livramento e os demais municípios do Brasil e do RS e os valores e utilizados. No ano de 2016 os valores repassados para Santana do Livramento ultrapassaram a média de valores transferidos para os municípios do Brasil. Nos demais anos os valores foram inferiores. Já os valores médios dos municípios do RS foram inferiores, em todo o período, aos valores repassados para Santana do Livramento.

Salienta-se que o município de Santana do Livramento não cumpriu a Lei 11.947/2009, uma vez que em nenhuma dos anos analisados o valor utilizado para aquisição da agricultura familiar atingiu 30\% dos recursos repassados pela União. Apesar de ser uma legislação que já completou dez anos de existência (de 2009), ainda necessita organização de gestores e agricultores para que seja efetivada nos diferentes contextos brasileiros, aumentando as possibilidades de contribuir para o desenvolvimento econômico local e para o fornecimento de refeições saudáveis nas escolas (SARAIVA, et al., 2013). A efetividade do PNAE depende de como ocorre a interação dos atores que fazem a gestão do programa em nível local (BASSO et al., 2019).

Figura 03 - Valores repassados e utilizados para compras da agricultura familiar no período de 2011 a 2016 no município de Santana do Livramento e médias dos municípios do RS e do Brasil

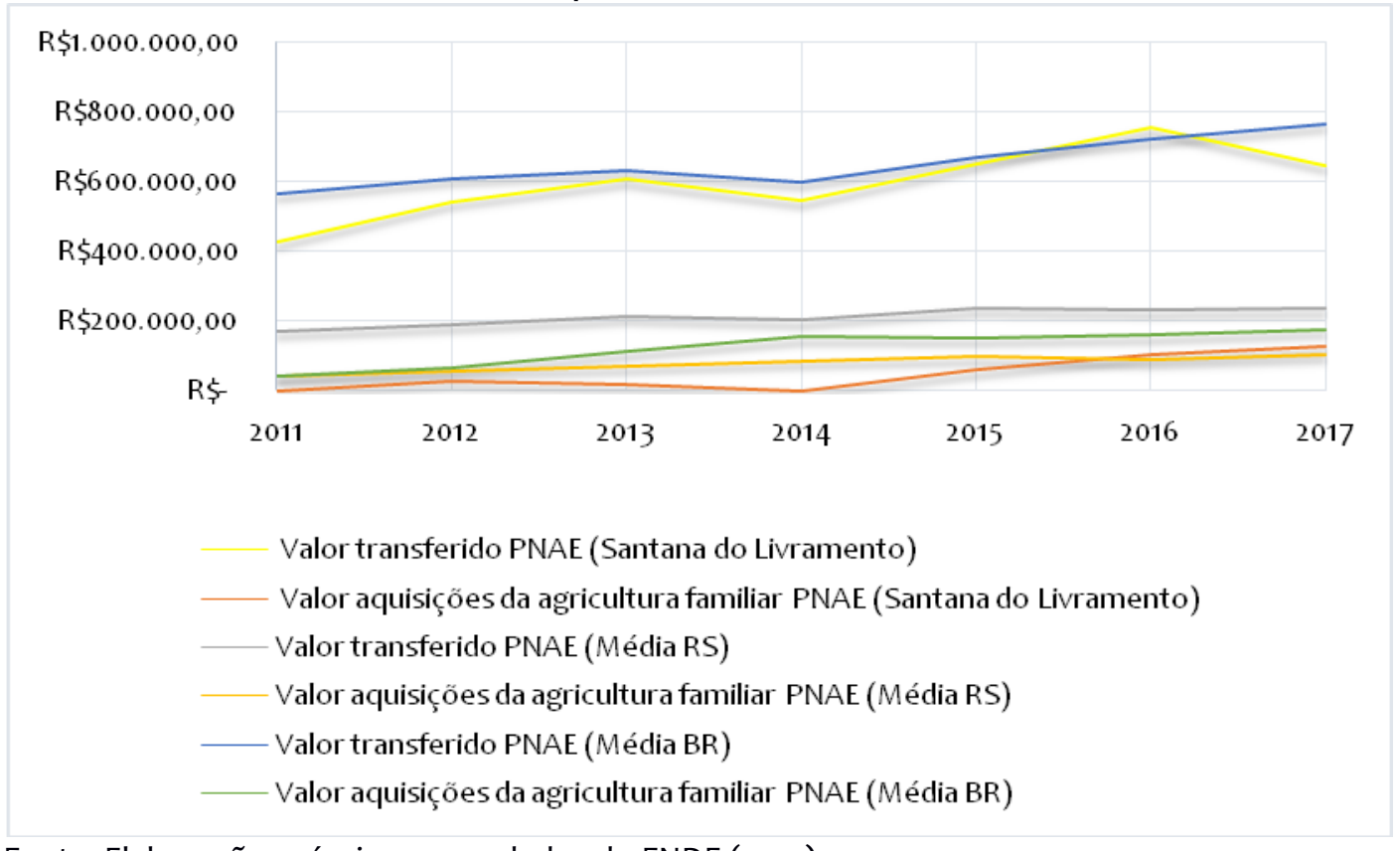

Fonte: Elaboração própria com os dados do FNDE (2017).

Apesar dos entraves, o PNAE fortalece a agricultura familiar e incentiva a formação de hábitos alimentares saudáveis. Ainda, legitima a sustentabilidade nas diferentes dimensões, pois regionaliza o fornecimento da alimentação escolar, contribui para manter o produtor e sua família no campo, inclui beneficiários e fornecedores, respeita culturas, tradições e comportamentos alimentares diferenciados (RIBEIRO; CERATTI; BROCH, 2013). No entanto, para a eficiência do PNAE é fundamental a continuidade, afirmação e a ampliação do programa a partir da atuação ativa dos gestores. 


\title{
4.1 Entraves e desafios do PNAE em Santana do Livramento/RS
}

Apesar dos inúmeros benefícios econômicos, sociais e de saúde dos alimentos adquiridos diretamente da agricultura familiar, os municípios brasileiros enfrentam dificuldades em cumprir a legislação (FERIGOLLO et al., 2017).

Em Santana do Livramento, o descumprimento da lei está atrelado a documentação necessária para a venda dos alimentos, a demora na elaboração e na divulgação dos editais, aos preços dos produtos, a falta de documentação da agricultura familiar local, e, em certa medida, a desconfiança ou o desconhecimento dos gestores com relação aos alimentos produzidos localmente.

A demora na elaboração dos documentos necessários para as chamadas públicas entre os setores internos da prefeitura e a falta de documentação por parte dos agricultores são os entrevas elencados por uma entrevistada:

\begin{abstract}
Porque é um processo bastante delicado o ano passado ele passava por dezenove setores até se efetuar na realidade a compra [...] este ano a gente tá tentando agiliza o máximo [...] este ano só vamos conseguir um resultado maior porque a gente tava, o prefeito tem cobrado bastante também e nós estamos em cima, mas às vezes senão esbarra no setor esbarra no outro, às vezes os próprios produtores eles não têm a documentação toda, entende. Então as dificuldades não são por parte da prefeitura é também dos fornecedores. (6 $6^{\mathrm{a}}$ ENTREVISTADA).
\end{abstract}

O preço dos alimentos fornecidos pelos agricultores familiares foi considerado como entrave para outra entrevistada, ao apontar que o valor cobrado pelos agricultores familiares inviabiliza a compra, já que eles são mais elevados que os preços de varejo.

Pelo valor [...] a gente entende que eles deveriam ser mais baratos, mas não, as vezes os deles são mais caros que no mercado [...] a gente precisa pegar o mais barato [...] ai a gente até não compra, compra deles sim, mas muito pouco $[\ldots]$ ( $4^{\circ}$ ENTREVISTADA).

O preço também aparece como um entrave na fala de outra participante da pesquisa. Segundo a entrevistada, o preço dos alimentos, juntamente com a sazonalidade dos produtos são os empecilhos para o cumprimento da Lei $\mathrm{n}^{\circ}$ 11.947/2009. "Os preços, as vezes a quantidade de produto, as vezes o produtor produz batata, e não tem outro, o tomate vamos supor, então a escola as vezes se limita ao que o produtor tem" ( $3^{\circ}$ ENTREVISTADA).

Toyoyoshi et al. (2013) realizaram pesquisa com os 1.082 municípios inscritos e os 22 municípios indicados a receber a premiação da Organização Não Governamental Ação Fome Zero, na $8^{a}$ edição (referente ao ano de 2011) que identifica e premia prefeituras com boas práticas de gestão pública municipal do Programa Nacional de Alimentação Escolar. Nessa pesquisa os autores constataram a necessidade de expansão na variedade e quantidade dos tipos de alimentos ofertados pelos agricultores para acesso ao PNAE. Para os autores, a limitada produção e a dificuldade dos municípios e dos agricultores nos processos das chamadas públicas, bem como na quantidade de alimentos necessários para suprir as escolas dificulta a aquisição dos alimentos da agricultura familiar para a merenda escolar. 
Rockett et al., (2019), a partir de estudo realizado no Rio Grande do Sul, destacam que uma porcentagem de municípios ainda não cumpre a exigência da legislação para atingir os 30\%, assim como Santana do Livramento. Por outro lado, a agricultora entrevistada na presente pesquisa menciona o quão positivo é para os agricultores familiares a comercialização via PNAE, do ponto de vista financeiro. Segundo a entrevistada, o preço dos alimentos vendidos para a merenda escolar é o preço estabelecido na chamada pública. "O cálculo, no caso o preço, o valor, já vem estipulado, mas é um preço bom, porque eu entrego a alface aqui em restaurante na cidade eu entrego a $R \$ 1,50$ e lá pra escola é $R \$ 2,50$ o valor, já vem estipulado na chamada pública, já vem o valor" ( $2^{\mathrm{a}}$ Entrevistada).

Portanto, a fala da agricultora confirma a forma utilizada pelas Entidades Executoras para definir os preços dos produtos adquiridos da agricultura familiar. Segundo o FNDE (2016), estes preços devem ser definidos previamente pela Entidade Executora e posteriormente são publicados no edital da Chamada Pública. Os produtos contratados no âmbito da Chamada Pública devem ter obrigatoriamente preços que reflitam os preços de mercado, determinados a partir de pesquisa realizada pela Entidade Executora. A pesquisa de preços deve ser realizada ao menos em três locais, sendo a média destes considerada para definir o preço, acrescentando os insumos exigidos no edital de chamada pública (por exemplo: despesas com frete, embalagem, encargos e quaisquer outros necessários para o fornecimento do produto). Quando houverem feiras de produtores da agricultura familiar, estas devem ser priorizadas nas pesquisas (FNDE, 2016).

O artigo 14 da lei $n^{\circ}$ 11.947/2009 abre o precedente para as compras públicas de alimentos para o PNAE de agricultores familiares sem necessidade de licitação (SCHABARUM; TRICHES, 2019). Para tanto, segundo as normas estabelecidas na lei, deve-se considerar todos os insumos utilizados, como despesas com frete, embalagens, encargos, entre outros custos necessários para o fornecimento do produto. Ou seja, estas despesas deverão ser acrescidas ao preço médio para definir o preço de aquisição dos produtos da agricultura familiar (BRASIL, 2015).

Os custos previstos na legislação, quando incorporados aos produtos da agricultura familiar, podem resultar no preço mais elevado do que o preço de mercado. Tal situação ganha destaque em Santana do Livramento, segundo maior município do estado, em extensão territorial do estado (IBGE, 2017), onde os produtores se localizam distantes do perímetro urbano, com vias de acesso mal conservadas. Somado a isso, a escala produtiva é baixa, o que reduz os ganhos quando comparados a empreendimentos maiores. Em contrapartida, os gestores escolares possuem recursos escassos e tendem a fazer alocação dos mesmos visando garantir a alimentação dos seus estudantes, descumprindo, dessa forma, a lei.

Souza (2012), em estudo realizado no estado de São Paulo e Prado et al., (2013) analisando os casos de Contagem e de Betim, na região metropolitana de Belo Horizonte, abordam o entrave da logística salientando que, em grande parte das negociações, os agricultores arcam sozinhos com custos além daqueles específicos da produção agropecuária. Torna-se oneroso para o produtor o fornecimento ao PNAE, principalmente de hortaliças e frutas in natura, produtos com preço baixo, sem valor agregado e de transporte delicado devido à alta perecibilidade. 
Outro fator limitante no município foi a resistência dos gestores na aquisição dos alimentos oriundos da agricultura familiar. Antes da implementação da Lei $n^{a}$ 11.947, a merenda escolar era produzida sem muita preparação e variação de cardápio. Após, há um novo cenário na alimentação escolar, os alimentos embutidos, enlatados e semi prontos passaram a ser substituídos por alimentos orgânicos e oriundos dos agricultores familiares. No entanto, a alimentação escolar se tornou um entrave, pois para a preparação do cardápio precisa maior capacitação do responsável e exige mais mão da obra. Segundo a agricultora entrevistada, tais elementos tornam-se barreiras para a compra da agricultura familiar e impedem os estudantes de terem uma alimentação saudável e de qualidade.

[...] coloca a questão do diretor, se eu comprar mandioca, eu vou ter que descascar ela, vou ter que lavar, botar pra cozinhar pra poder fazer comida, mas se me chegar uma lata de três quilos de ervilha, é mais fácil de eu colocar na panela[...] ( $2^{\mathrm{a}}$ ENTREVISTADA).

Conforme Triches et al., (2018), a ausência de diálogo entre os diferentes setores da administração pública local, aliada às dificuldades de logística de distribuição dos produtos e refeições, limita o potencial de demanda. Para os autores, a rigidez dos cardápios, influenciada por uma cultura conservadora por parte de nutricionistas, interfere diretamente na cesta de produtos demandados da agricultura familiar.

A documentação necessária para os agricultores participarem das chamadas públicas e o uso de agrotóxicos foram os entraves elencados por um dos entrevistados. Segundo o entrevistado não são todos os agricultores que possuem o bloco do produtor em dia, além do fato de haver produção de soja no município com elevados índices de agrotóxicos e ela estar contaminando a produção de alimentos.

\footnotetext{
Olha o maior é, toda documentação, todo agricultor tem que estar em dia com o talão, tudo certinho para vender, e eles também tem que ser livre de veneno, esse é um dos grandes problemas que esta se enfrentando em todo meio rural de Santana do Livramento, e a plantação da soja, dificilmente vai ter uma hortinha que não tem uma lavoura de soja do lado, isso vai ser um grande entrave para o futuro ( $1^{\circ}$ Entrevistado).
}

Marques et al., (2014), em estudo realizado sobre a dinâmica de fornecimento de produtos da agricultura familiar no município de Araripe/Ceará, apontam a dificuldade dos agricultores se manterem no PNAE. Apresar de ter capacidade produtiva para escoar a produção para as escolas municipais, os agricultores preferem permanecer fora desse mercado, devido a quantidade de documentos e papelada necessária. Conforme Souza (2012), Bacarin et al., (2012), Marques et al., (2014), Rozendo, Bastos e Molina (2014), entre outros, muitos documentos precisam ser criados para permitir a inserção dos agricultores no PNAE.

Corroborando com essas afirmações, Camargo, Baccarin e Silva (2013) destacam que no estado de São Paulo o acesso aos marcados institucionais é restrito a um baixo número de produtores devido as seguintes dificuldades: a) custo da participação em reuniões de associações, cooperativas, etc.; b) falta de conhecimento e domínio das normas que regem a administração pública; c) burocracia. 
Saraiva et al., (2013), em estudo de nível nacional com dados de 2010, constatou que as instituições municipais brasileiras que tiveram dificuldade em cumprir a lei justificaram alegando a falta de fornecimento regular e constante de alimentos por parte da agricultura familiar. No entanto, os autores destacam que o ano de 2010 foi o primeiro ano de obrigatoriedade da compra da agricultura familiar e que a cada ano, novos avanços vêm sendo construídos. Segundo Rockett et al., (2009), o principal desafio para a aquisição de alimentos da agricultura familiar no RS foi a falta de organização dos agricultores. Porém, no início do programa em 2010, a região Sul foi a que mais adquiriu alimentos da agricultura familiar, pela maior organização dos agricultores e gestores (SARAIVA et al., 2013).

Ainda, como entrave para a aquisição de produtos diretamente da agricultura familiar para a merenda escolar, apareceram as limitações financeiras e de veículos de transporte. Segundo um entrevistado as escolas não conseguem acessar a sede da cooperativa', local onde são realizadas as transações entre as escolas e os agricultores.

\begin{abstract}
A principal dificuldade é assim, a escola ela tem um valor, que é aquilo que a gente recebe, mas nós não temos os meios, e esta dificuldade não é só com relação à alimentação, assim ó a maior dificuldade com a agricultura familiar é que, por exemplo, o leite tá, numa chácara lá pro lado da chácara da prefeitura, pro lado do presidio e nós não tínhamos veículo [...] pra fazer a licitação pra eu ir lá pra pagar ou pra pedi uma assinatura..." ( $5^{\circ}$ Entrevistado).
\end{abstract}

Baccarin et al., (2012) apontam alguns gargalos na operacionalização do PNAE, destacando-se: falta de planejamento; dificuldades de acesso e entendimento das chamadas públicas; excesso de normatização/burocracia no programa; dificuldades de logística e adequação com a padronização dos alimentos. Para Rockett et al., (2019), os principais entraves na aquisição de alimentos da agricultura família estão relacionados à falta de preparo dos agricultores, ao padrão de qualidade e aos registros de produtos e estabelecimentos em Associações ou Cooperativas. Tais obstáculos criam lacunas entre os interlocutores do programa, dificultando o desenvolvimento da economia local

Segundo Rockett et al., (2019), as justificativas apresentadas pelos municípios gaúchos para o descumprimento da Lei n 11.947/2009, são problemas com documentação como falha na emissão de nota fiscal, condições higiênicosanitárias insatisfatórias e produtores que não quiseram fornecer alimentos para o PNAE. Em Santana do Livramento a justificativa dada pelo setor público para descumprindo da lei não fica evidente. "Por enquanto ainda não perdemos (os recursos), tu me entende sempre tem uma justificativa mas é arriscado, é isso que a gente vai tenta [...]" (6 $6^{a}$ Entrevistada). Os argumentos usados para os órgãos de controle é que as escolas recebem doações de alimentos, que o preço dos alimentos da agricultura familiar local é mais elevado, entre outros, os quais não ficaram claros no decorrer da entrevista.

\footnotetext{
${ }^{1}$ COPERFORTE - Cooperativa Regional dos Assentados da Fronteira Oeste.
} 
As vezes as nutricionistas da SEDUC ${ }^{2}$, mandam um relatório pra nós dizendo que a escola não ta cumprindo, algumas escolas mandam as justificativas, olha algumas escolas por exemplo, escolas do campo, elas acabam não comprando os $30 \%$, porque as vezes elas tem horta, tem doação de pessoas vizinhas [...] as vezes tem (que justificar) porque que a escola não está fazendo a compra dos $30 \%$, e ai a gente justifica pra elas isso, só que ai se depara com a mesma questão da realidade que eu te falei, a gente lembra, a gente avisa, as vezes, não conseguimos tomar outras providencias diante da realidade da escola. ( $3^{\mathrm{a}}$ Entrevistada)

$\mathrm{Na}$ fala da entrevistada percebe-se que a secretaria faz o esforço de informar as direções de escolas acerca da necessidade da compra direta dos agricultores familiares. No entanto, segundo a entrevistada, a decisão de como, o que comprar e onde gastar os recursos recebidos via PNAE é de cada diretor. Destaca-se que a dinâmica da alimentação escolar no município é escolarizada, ou seja, a secretaria de educação repassa os recursos recebidos do FNDE e cada escola, através de suas direções é responsável pela aquisição dos alimentos para a merenda escolar.

Assim, os alimentos fornecidos nas escolas de Santana do Livramento são adquiridos em padarias, açougues e supermercados locais, apenas uma pequena parte dos alimentos é adquirida da agricultura familiar. "Olha, os locais da cidade, acredito que supermercados, esses que vendem por atacado, ou fornecedores, eu não sei te informar bem como as escolas fazem essas compras" ( $3^{\text {a }}$ Entrevistada). Os produtos passam por um processo licitatório e a organização que ofertar o produto pelo menor valor ganha a licitação, seja ele de Santana do Livramento ou não.

Os alimentos fornecidos pelos agricultores familiares são diversos, alternam de acordo com o produtor e a demanda da escola. "No meu lote é verduras em geral, couve, alface, tempero verde, repolho, frutas, mandioca, batata e milho verde, cabotia, isso eu estou dentro da tomada de preço, esses produtos eu tenho que entregar" ( $2^{\text {a }}$ Entrevistada).

Para um entrevistado a merenda ofertada na escola rural em que ele atua é majoritariamente oriunda da agricultura familiar. "A alimentação grossa, como o arroz o feijão vem dos supermercados, agora tudo que é de origem primária, sem ser industrializado, vem de lá de fora, e tudo comprado da agricultura familiar" $\left(1^{\circ}\right.$ Entrevistado).

A fala dos entrevistados indica que existem formas distintas das escolas perceberem e se relacionarem com a agricultura familiar. As escolas urbanas têm dificuldade em comprar os alimentos da agricultura familiar, enquanto nas escolas rurais, com estudantes e professores com origens na agricultura, esse processo ocorre naturalmente. Mesmo o preço dos produtos da agricultura familiar sendo igual para todas as escolas, as escolas urbanas têm resistência na aquisição dos alimentos da agricultura familiar local. Ainda, há um descompasso entre a secretaria e as escolas, sejam rurais ou urbanas, pois os discursos dos entrevistados são, em certa medida, contraditórios. Segundo a agricultora entrevistada, ela passou a comercializar via PNAE pelo interesse e dedicação da diretora da Escola Antônio

\footnotetext{
${ }^{2}$ Secretaria de Educação.
} 
Conselheiro, Escola Estadual de $1^{\circ}$ e $2^{\circ}$ graus que se localiza no meio rural de Santana do Livramento.

[...] a gente come bem em casa, os nossos filhos também estão aqui e tão vendo na sala de aula, então tem que comer bem, então a professora, a diretora começou a ir atrás, ela foi atrás e do município, estado e tal, e ficou sabendo que era obrigatoriamente né sendo que adquirido $30 \% \mathrm{da}$ alimentação da escola tinha que vim da agricultura familiar, através do projeto, e ai ela trouxe para dentro da escola, e começou a fazer tudo o que precisava, papéis, documento. Mas assim, talvez porque seja uma escola diferenciada, dentro de assentamento, com uma diretora com esse perfil $[\ldots]$ ( $2^{\mathrm{a}}$ Entrevistada).

A compra da agricultura familiar demanda preocupação com o que os estudantes estão comendo, boa vontade e dedicação da direção escolar em dialogar com os produtores locais para apresentar a demanda e auxiliá-los a organizar a documentação necessária para a comercialização via PNAE. Para viabilizar o crescimento do mercado de compras públicas da agricultura familiar é fundamental: a) aprimorar a estrutura logística de apoio (transporte, beneficiamento e armazenamento); b) ampliar parcerias (governos estaduais, municipais, organizações de produtores, organizações não governamentais (ONGs) e instituições diversas); c) coordenar as ações governamentais para melhorar a assistência técnica e oferta de crédito; d) os bancos considerem projetos de crédito para sistemas de produção consorciados, considerando o todo da unidade produtiva (SAMBUICHI et al., 2014).

Por fim, a agricultura familiar quando apoiada por políticas públicas adequadas é capaz de fornecer alimentos diversificados para garantir a segurança alimentar (SAMBUICHI et al., 2014). No entanto, para isso ocorrer, é preciso conhecimento, organização e boa vontade dos gestores escolares e dos agricultores familiares. É fundamental o diálogo entre eles, já que as trocas poderão impulsionar o desenvolvimento em Santana do Livramento e na metade Sul do estado como um todo.

\section{CONSIDERAÇÕES FINAIS}

O Programa Nacional de Alimentação Escolar, ao longo da história, comprovou sua relevância. No que concerne a qualidade dos alimentos ofertados na merenda escolar, as últimas décadas apresentam as alterações mais relevantes, sobretudo constituindo-se como uma política de desenvolvimento, já que vincula produtor e consumidor. Apesar da relevância da alteração legal realizada em 2009, incluindo a agricultura familiar como ofertante dos alimentos, ainda diversos municípios brasileiros não têm cumprido a lei e adquirindo menos de $30 \%$ do valor repassado pela União para a aquisição dos alimentos diretamente da agricultura familiar.

O município de Santana do Livramento está entre estes casos. Apesar de Santana do Livramento demonstrar evolução na utilização do recurso, de 2014 a 2017, a utilização máxima no período analisado foi em 2017 em que usou 19,49\% do recurso repassado pela União para compra direta da agricultura familiar via PNAE. As médias anuais estadual e nacional de utilização do recurso do PNAE para 
aquisição da agricultura familiar são superiores às médias de Santana do Livramento.

Os entraves enfrentados pela gestão pública municipal que resultam no descumprimento da Lei 11.947/2009 são os atrasos da prefeitura no lançamento das chamadas públicas, a falta de documentação dos agricultores, o preço dos produtos da agricultura familiar e o desconhecimento e descrédito na agricultura familiar local.

O que se constata em Santana do Livramento é um desencontro entre as políticas públicas de alimentação escolar, especificamente o PNAE, a gestão escolar e o poder público municipal. A presente pesquisa constatou que não ocorre como esperado e de forma adequada uma contrapartida da prefeitura, como infraestrutura de estradas, assistência técnica e demais condições de produção, transporte e assistência aos agricultores familiares.

Para que a lei dos 30\% do PNAE seja cumprida no município é preciso um esforço dos gestores locais. Estes precisam se envolver no processo de construção local de uma produção forte e estruturada, aliada a uma demanda que valorize a produção de alimentos da agricultura familiar. No entanto, para que isso ocorra, há a necessidade de romper com a visão antiquada e, porque não dizer preconceituosa, acerca da agricultura familiar, já que as ações e políticas locais deixam transparecer a invisibilidade da categoria social, que ocorre historicamente no município. Neste sentido, é urgente o reconhecimento do papel e a importância da agricultura familiar no processo de desenvolvimento. Sobretudo, é fundamental o diálogo entre os agentes locais para construir uma cadeia de comercialização que atenda às necessidades de todos os envolvidos.

\section{REFERÊNCIAS}

BACCARIN, J. G. et al. Agricultura familiar e alimentação escolar sob a vigência da Lei 11.947/2009: adequação das chamadas públicas e disponibilidade de produtos no estado de São Paulo em 2011. In: Anais... L Congresso da SOBER, Espírito Santo, de 22 a 25 de julho, 2012.

BASSO, David; LOPES, Indaia Dias; AMARAL, Volmir Ribeiro do. Reflexões sobre a operacionalização do PNAE nas Escolas Estaduais de Passo Fundo (RS). Redes (St. Cruz Sul, Online), Santa Cruz do Sul, v. 24, n. 1, p. 163-186, jan. 2019. ISSN 1982-6745. Disponível em: https://online.unisc.br/seer/index.php/redes/article/view/11272 Acesso em: 20 mar. 2020. doi: https://doi.org/10.17058/redes.v24i1.11272

BECKER, C.; SACCO DOS ANJOS, F. São os mercados institucionais da agricultura familiar um instrumento para o desenvolvimento rural? Estudo de caso em municípios do sul do Brasil. Revista de la Facultad de Agronomía, La Plata, v. 114, n. 1, p. 143-152, 2015.

BELIK, W., SOUZA, L. Algumas reflexões sobre os programas de alimentação escolar na América Latina. Planejamento e Políticas públicas. n. 33. Brasília, IPEA, jul./dez., 2009. 
BRASIL. Lei n 11.947, de 16 de junho de 2009. Diário Oficial [da] República

Federativa do Brasil, Brasília, DF, 17 jun. 2009.

BRASIL. MINISTÉRIO DA EDUCAÇÃO (MEC). Programa Nacional de Formação Continuada a Distância nas Ações do FNDE. Fundo Nacional de Desenvolvimento da Educação. Secretaria de Educação a Distância - 2.ed., atual. - Brasília: MEC, FNDE, SEED, 2008.

CAMARGO, R. A. L et al. O papel do Programa de Aquisição de Alimentos (PAA) e do Programa Nacional de Alimentação Escolar (PNAE) no fortalecimento da agricultura familiar e promoção da segurança alimentar. Revista Temas de administração Pública, Araraquara-SP, v.8, n.2, p.1-21, 2013.

CHAVES, L. G. et al. O programa nacional de alimentação escolar como promotor de hábitos alimentares regionais. Revista de nutrição, Campinas, v. 22, n. 6, p. 857-866, nov./dez., 2009.

CHAVES, L. G.; BRITO, R. R. Políticas de Alimentação Escolar. Brasília: Centro de Educação a Distância - CEAD, Universidade de Brasília, 2006.

CRESWELL, J. W. Projeto de pesquisa: métodos qualitativo, quantitativo e misto. Porto Alegre: Artmed, 2007.

FERIGOLLO, D., et al. Aquisição de produtos da agricultura familiar para alimentação escolar em municípios do Rio Grande do Sul. Rev Saúde Pública, São Paulo, v. 51, n. 6, p.1-10, 2017.

FAO. Organização das Nações Unidas para a Alimentação e a Agricultura /INCRA. Projeto de cooperação técnica INCRA/ Organização das Nações Unidas para a Alimentação e a Agricultura. Novo retrato da agricultura familiar. O Brasil redescoberto. Brasília, 2014.

FUNDO NACIONAL DE DESENVOLVIMENTO DA EDUCAÇÃO (FNDE). Aquisição de produtos da agricultura familiar para a alimentação escolar. $2^{\mathrm{a}}$ edição - versão atualizada com a Resolução CD/FNDE nº 04/2015, Brasília, 2016.

FUNDO NACIONAL DE DESENVOLVIMENTO DA EDUCAÇÃO (FNDE). Alimentação escolar. 2017. Disponível em: <http://www.fnde.gov.br/programas/pnae>. Acesso: 20 de out. 2017.

FUNDO NACIONAL DE DESENVOLVIMENTO DA EDUCAÇÃO (FNDE). Ministério da Educação. Desenvolvimento da Agricultura Familiar do Programa Nacional de Alimentação Escolar/ FNDE. Aquisição de produtos da agricultura familiar para a alimentação escolar. Manual. Brasília, 2014. 
MALINA, L. L. Chamada Pública: Instrumento Legal de Compras da Agricultura Familiar para a Alimentação Escolar. In: CORÁ, M. A. J.; BELIK, W. (Orgs). Projeto Nutre SP: Análise da inclusão da agricultura familiar na alimentação escolar no estado de São Paulo. São Paulo: Instituto Via Pública, 2012.

MARQUES, A. de A. et al. Reflexões de agricultores familiares sobre a dinâmica de fornecimento de seus produtos para a alimentação escolar: o caso de Araripe, Ceará. Saúde e Sociedade, São Paulo, v.23, n.4, p.1329-1341, 2014.

MINISTÉRIO DO DESENVOLVIMENTO AGRÁRIO. Secretaria da Agricultura Familiar. Declaração de Aptidão ao Pronaf. Brasília, DF, 2017. Disponível em: <http://www.mda.gov.br/sitemda/saf/dap>. Acesso em: 17 de jun. de 2017.

MÜLLER, A. L. Programa de Aquisição de Alimentos da Agricultura Familiar e Programa Nacional de Alimentação Escolar. Relatório de Consultoria. Brasília, 2010

PEDRAZA, D. F. et al. Avaliação do Programa Nacional de Alimentação Escolar: revisão da literatura. Ciência e Saúde Coletiva, Rio de Janeiro, v. 23, n. 5, p.1551-1560, 2018.

PEIXINHO, A. M. L. A trajetória do Programa Nacional de Alimentação Escolar no período de 2003-2010: relato do gestor nacional. Ciência e Saúde Coletiva, Rio de Janeiro, v.18, n.4, p.909-916, 2013.

PEREIRA, J.C et al. Agricultura familiar e mercados institucionais: analise do Programa Nacional de Alimentação Escolar (2009 a 2014). In: Anais.... 56 Congresso da Sociedade Brasileira de Economia, Sociologia e Administração Rural, Campinas, de 29 de jul a 1 de ago de 2018.

PRADO, T. R. et al. Agricultura familiar na alimentação escolar: estudo de caso em dois municípios de Minas Gerais. Nutrire, São Paulo, v. 38, n. 3, p. 256-268, dez. 2013.

RIBEIRO, A. L. de P. et al. Programa Nacional de Alimentação Escolar (PNAE) e a participação da agricultura familiar em municípios do Rio Grande do Sul. Revista Gestão e Desenvolvimento em Contexto, Cruz Alta/RS, v.1, n.1, p.1-14, 2013.

ROCKETT, F. C et al. Agricultura familiar e merenda escolar no Rio Grande do Sul, Brasil. Cienc. Rural, Santa Maria/RS, v .49 n.2, p.5-12, mar, 2019.

ROZENDO, $C$ et al. A implementação das novas diretrizes do PNAE: desafios institucionais. In: ENCONTRO DA REDE DE ESTUDOS RURAIS, 6, Campinas, 2014. Anais..., Campinas/SP. 2014

SAMBUICHI, R. H. R. et al. (Org). Políticas Agroambientais e Sustentabilidade: desafios, oportunidades e lições aprendidas. Brasília: Ipea, 2014. 
SARAIVA, E. B. et al. Panorama da compra de alimentos da agricultura familiar para o Programa Nacional de Alimentação Escolar. Ciência e saúde coletiva, Rio de Janeiro, v.18, n.4, p.927-935, 2013.

SCHABARUM, J.C.; TRICHES, R. M. Aquisição de Produtos da Agricultura Familiar em Municípios Paranaenses: análise dos produtos comercializados e dos preços praticados. RESR, Piracicaba/SP, v. 57, n. 01, p. 049-062, jan./mar. 2019.

SCHNEIDER, S.; ESCHER, F. A contribuição de Karl Polanyi para a sociologia do desenvolvimento rural. Sociologias, Porto Alegre, v.13, n. 27, p.180-220, maio/ago. 2011.

SOARES, P. et al. Potencialidades e dificuldades para o abastecimento da alimentação escolar mediante a aquisição de alimentos da agricultura familiar em um município brasileiro. Ciência e Saúde Coletiva, Rio de Janeiro, v. 20, n. 6, 1. 18911900, 2015.

SOUZA, L. B. B. Organizações da agricultura familiar no Estado de São Paulo e sua experiência de fornecimento para o PNAE. In: CORÁ, M. A. J.; BELIK, W. (org.).

Projeto Nutre SP: análise da inclusão da agricultura familiar na alimentação escolar no estado de São Paulo. Brasília (DF): Ministério do Desenvolvimento Agrário, 2012.

STEFANINI, M.L.R. Merenda Escolar: História, Evolução e Contribuição no Atendimento das Necessidades Nutricionais da Criança. 1997. Tese (Doutorado em Nutrição). Universidade de São Paulo, São Paulo, 1997.

TOYOYOSHI, J.Y. et al. Avaliação da aquisição de gêneros alimentícios provenientes da agricultura familiar para a alimentação escolar. Mundo Saude. v.37, n. 3, p. 329335, 2013.

TRICHES, R. M.; SCHNEIDER, S. Alimentação escolar e agricultura familiar: reconectando o consumo à produção. Saúde e Sociedade, São Paulo, v. 19, n. 4, p. 933-945, out./dez. 2010.

TRICHES, R. M.; SCHNEIDER, S. Reconstruindo o "elo perdido": a reconexão da produção e do consumo de alimentos através do Programa de Alimentação Escolar no município de Dois Irmãos (RS). Revista Segurança Alimentar Nutricional. Campinas/SP, v.17, n.1, p.1-15, jan. 2010.

TROIAN, A.; BREITENBACH, R. Estratégias e formas de reprodução social na agricultura familiar da Fronteira Oeste do Rio Grande do Sul. Novos Cadernos NAEA, Belém. v.21, p.139 - 158, 2018. 
Alessandra Troian. Doutora em Desenvolvimento Rural, professora adjunta na Universidade Federal do Pampa, campus Santana do Livramento. alessandratroian@unipampa.edu.br

Raquel Breintenbach. Instituto Federal de Educação, Ciência e Tecnologia do Rio Grande do Sul.

Como citar: TROIAN, Alessandra; BREINTENBACH, Raquel. O Programa Nacional de Alimentação Escolar em Santana do Livramento (RS): Desafios para a Adequação à Lei dos 30\%. Redes (St. Cruz Sul, Online), Santa Cruz do Sul, v. 25, n. 2, p. 570-589, abr. 2020. ISSN 1982-6745. Disponível em: https://online.unisc.br/seer/index.php/redes/article/view/14848 Acesso em: 15 maio 2020. doi: https://doi.org/10.17058/redes.v25i2.14848

\section{CONTRIBUIÇÃO DE CADA AUTOR}

a. Fundamentação teórico-conceitual e problematização: Alessandra e Raquel

b. Pesquisa de dados e análise estatística: a coleta de dados secundários foi realizada pela Raquel os dados primários por mim, Alessandra.

c. Elaboração de figuras e tabelas: Alessandra e Raquel

d. Fotos: Alessandra

e. Elaboração e redação do texto: Alessandra e Raquel

f. Seleção das referências bibliográficas: Alessandra e Raquel

Fontes de financiamento: a pesquisa foi realizada com recursos próprios das pesquisadoras. 